\title{
ANÁLISE COMPARATIVA DO USO DE REDES SOCIAIS COMO CANAL DE MARKETING POR EMPRESAS BRASILEIRAS DE COMÉRCIO ELETRÔNICO
}

\author{
${ }^{1}$ Colégio Técnico Industrial de Santa Maria - CTISM, glaucop10@ redes.ufsm.br \\ Universidade Federal de Santa Maria - UFSM - Santa Maria/RS - Brasil \\ ${ }^{2}$ Programa de Pós-Graduação em Administração- PPGA, eosimonetto@gmail.com \\ Universidade Federal de Santa Maria - UFSM - Santa Maria/RS - Brasil \\ ${ }^{3}$ Colégio Técnico Industrial de Santa Maria - CTISM, celsosb@yahoo.com.br \\ Universidade Federal de Santa Maria - UFSM - Santa Maria/RS - Brasil
}

Glauco Oliveira RODRIGUES

Eugênio de Oliveira SIMONETTO

Celso Silva BROSSARD ${ }^{3}$

\section{Recebido em: 30/05/2014 - Aprovado em: 30/06/2014 - Disponibilizado em: 30/07/2014}

RESUMO:Com o surgimento e posterior popularização das redes sociais, as empresas vêm utilizando cada vez mais essa nova mídia para se aproximar de seus clientes. Nesse sentido, este estudo buscou fazer uma analise comparativa do uso do Facebook e do Twitter como um canal de marketing, através da analise da utilização dessas ferramentas por empresas que se utilizam do comércio eletrônico. Para o estudo, foram realizadas coletas diárias de dados, tanto no Facebook quanto no Twitter, como quantidade de posts e tweets, horário e dia das ações, durante trinta dias. Os dados foram analisados e comparados em uma pesquisa qualitativa e quantitativa. Como resultado dessa análise, observou-se que apesar das empresas utilizarem mais o Twitter para chegar até seus clientes, existem similaridades no uso das duas redes sociais, por exemplo, as duas redes sociais fora usadas principalmente para enviar informativos aos clientes e o turno mais utilizado para essas ações foi o turno da tarde.

Palavras-chave: Comércio eletrônico. Mídias sociais. Redes sociais. Facebook. Twitter.

\section{COMPARATIVE ANALYSIS OF THE USE OF SOCIAL MEDIA AS A MARKETING TOOL FOR BRAZILIAN COMPANIES E-COMMERCE}

\begin{abstract}
With the advent and subsequent popularity of social networks, companies are increasingly using this new media to get closer to your customers. Accordingly, this study sought to make a comparative analysis of the use of Facebook and Twitter as a marketing channel, through an analysis of the use of these tools by companies that use the ecommerce For the study, daily collection of data, both on Facebook and on Twitter, like amount of posts and tweets, time and day of action for thirty days were accomplished. The data were analyzed and compared in a qualitative and quantitative research. As a result of this analysis, it was observed that although most companies use Twitter to reach their customers, there are similarities in the use of the two social networks, for example, the two social networks primarily used to send out newsletters to customers and more used to turn these actions was the afternoon.
\end{abstract}

Keywords: E-commerce. Social media. Social networks. Facebook. Twitter. 


\section{Introdução}

Com o crescimento da internet a sua popularização foi inevitável. Esse universo virtual está atingindo cada vez mais pessoas, sendo elas de todas as idades e posições sociais. $\mathrm{Na}$ internet o acesso e troca de informação com as outras pessoas está cada vez mais ágil e fácil, era apenas uma questão de tempo até as empresas enxergarem o grande potencial econômico que apresenta- se na Web, usando a rede para aproximar-se de seus clientes, ampliar suas vendas e lucros. Com o crescimento do comércio eletrônico (CE) o consumidor adaptou-se rapidamente à comodidade que as compras online podem oferecer, onde pode-se facilmente acessar produtos e promoções. O CE é considerado a mudança mais profunda no mundo dos negócios, afetando diretamente as empresas, desde o marketing até os setores financeiro e contábil, sua evolução atinge praticamente todas as organizações.

Segundo Reed (2012), a mídia social é simplesmente um conjunto de ferramentas e plataformas online, gratuitas que as pessoas utilizam para publicar, conversar e compartilhar conteúdo online. Essa afirmação nos mostra como as mídias e redes sociais podem ser utilizadas como um canal de marketing dentro do CE, de uma forma simples e de baixo custo. Nesse segmento o Facebook e o Twitter se destacam como ferramentas amplamente utilizadas pelas empresas para essa finalidade.

Este artigo tem como objetivo analisar a atuação das empresas, no atual marketing eletrônico, dentro do Facebook e do Twitter, bem como fazer uma comparação das ações tomadas pelas empresas dentro das duas redes sociais analisadas. A organização do mesmo encontra-se assim disposta: $\mathrm{Na}$ seção 2 abordar-se-á o conceito das redes sociais, o tópico comércio eletrônico será abordado na seção 3. Na seção é apresentado o método da pesquisa realizada. Os resultados da comparação são apresentados na seção 5, diferenciando-as e, também, demonstrando suas similaridades. Por fim, na seção 6, são apresentadas as considerações finais.

\section{Redes Sociais}

As redes sociais são mídias modernas através das quais as pessoas interagem umas com as outras. Elas permitem que qualquer usuário possa utilizar as ferramentas disponibilizadas por elas para estabelecer ligações com outros usuários localizados em diferentes locais do mundo. As redes sociais podem ser classificadas em vários níveis, dentre eles destacam-se: Redes de relacionamentos (Facebook, Orkut, Twitter), redes profissionais (LinkedIn), redes comunitárias (redes sociais em bairros ou cidades), redes políticas, etc. O principal elemento no qual ficam registrados todos os 
dados pessoais de determinada pessoa é chamada de perfil do usuário, através desse perfil a pessoa pode identificar outros usuários com gostos, atividades, etc. em comum.

Segundo RAMALHO (2012), as redes sociais são a essência das mídias sociais e promove a socialização entre amigos, colegas e outras pessoas. No caso de negócios, as redes sociais são o meio de atendimento ao consumidor mais eficiente nos dias de hoje. (ECOMMERCE, 2012)

Hoje o trabalho informal em rede é uma forma de organização humana presente em nossa vida cotidiana e nos mais diferentes níveis de estrutura das instituições modernas (MARTELETO 2009).

\subsection{Facebook}

O Facebook é uma rede social criada em 4 de fevereiro de 2004 por Mark Zuckerberg, Dustin Moskovitz e Chris Hughes, ambos alunos da Universidade de Harvard. Desde seu princípio, o Facebook tinha como objetivo configurar um espaço onde as pessoas poderiam encontrar seus amigos e, com isso, dividir opiniões e fotografias. Até chegar ao ano de 2014, o Facebook sofreu grandes mudanças, já que em seu inicio o acesso para essa rede social era permitido somente para os alunos da Universidade de Harvard. Aos poucos sua expansão foi aumentando Permitindo o acesso de outros institutos e universidade, e finalmente, no dia 27 de fevereiro, o site permitiu que alunos secundários e trabalhadores de empresas também tivessem acesso à rede. Assim, todas as pessoas acima de 13 anos podem se conectar nessa rede social.

O Facebook é uma ferramenta que permite que você mantenha uma rede de contatos, tanto pessoais como profissionais, oferecendo serviços como: Bate papo entre amigos, compartilhamento de fotos e vídeos, jogos, etc. Além de oferecer várias opções de ações que podem ser utilizadas no marketing, como criação de grupos e páginas promocionais. Segundo Reed (2012), o Facebook tornou-se uma das ferramentas de marketing online mais amplamente utilizadas por empresas.

\subsection{Twitter}

"O Twitter é uma rede social que permite aos usuários o envio e leitura de atualizações pessoais de, no máximo, 140 caracteres, os quais podem ser textos, links ou até mesmo fotos/imagens. Possui características mais simples que as redes sociais tradicionais, mas ao mesmo tempo é atraente podendo ser enquadrada à categoria de meios de comunicação social (COMM, 2010). Foi lançado em 2006, mas foi em 2009 que começou a tornar-se popular" (PETRY, SIMONETTO, 2013).

O Twitter foi desenvolvido pelos programadores Van Williams, Jack Dorsey e Biz Stone, segundo Reed (2012), é utilizado de maneiras criativas tanto por pessoas como por empresas para fazer conexões, criar seguidores fiéis, desenvolver feed de 
notícias úteis além de compartilhar links para artigos, imagens, áudios e vídeos.

"A principal característica do Twitter em relação a outras redes sociais é a possibilidade da unilateralidade. Em redes sociais como o Orkut ou o Facebook, é necessário que haja um vínculo de amizade virtual para que seja possível acessar informações dos usuários. No Twitter, ao escolher "seguir" uma pessoa, você irá acompanhar as atualizações de um determinado usuário, e esse será notificado por e-mail que você o está "seguindo". E cabe ao usuário decidir se quer segui-lo ou não" (PETRY,SIMONETTO, 2013).

\section{Comércio Eletrônico}

Comércio Eletrônico (CE) ou E-commerce é a forma de realizar negócios entre empresa e consumidor (B2C) ou entre empresas (B2B), usando a Internet como plataforma de troca de informações, encomenda e realização das transações financeiras (CAMPANO, 2009). A criação do $\mathrm{CE}$ foi uma das mudanças mais significativas ocorridas no mundo dos negócios, tornando o processo de venda fácil, rápido e seguro, reduzindo os custos das empresas que atuam neste segmento e estimulando a competitividade.

$\mathrm{O} \mathrm{CE}$ oferece muitas vantagens para as empresas. Entre essas destacam-se: disponibilidade de ofertas 24 horas, 7 dias por semana, diminuição dos custos associados com o cliente e com o fornecedor, facilidade no acesso a novos mercados e clientes, rapidez na divulgação de novos produtos e promoções.
Para os consumidores, as vantagens do CE também são evidentes, vantagens como compras mais eficientes, maior leque de escolhas, preços mais baixos e serviços personalizados. Além disso, oferece novos tipos de produtos e serviços, assim como novas maneiras de adquiri-los.

Segundo CAMPANO (2009), nos dias de hoje, a Internet não é um canal de comunicação para ser subestimado e cada vez mais as empresas utilizam-na como parte integrante da sua estratégia de marketing e publicidade. A diminuição de custos, uma audiência mais elevada e um grau superior de interatividade com o cliente/visitante são apenas alguns dos aspectos que elevam a Internet, nos dias de hoje, ao mesmo nível que outras formas de comunicação e marketing regularmente utilizadas.

Neto et al.(2010) afirma que o CE exige das empresas uma reestruturação estratégica, reengenharia de processo, estudo constante da cadeia de valor, realização de parcerias e foco na atitude dos clientes.

\subsection{Comércio Eletrônico e Marketing no Facebook}

O Facebook vem se mostrando um ótimo canal de marketing e venda online, muitas empresas e agências de marketing já estão incluindo o Facebook em suas campanhas. É importante colocar sua marca em evidência e o mais perto possível dos seus 
consumidores, o Facebook é uma grande oportunidade que não deve ser ignorada.

Segundo Ramalho (2010), o Facebook é uma rede social que agrega todo tipo de usuário. Entre todos os seus usuários podem existir muitos que gostem de um assunto específico que podem criar um grupo de interesse dentro do próprio site. Dentro do comércio eletrônico e do marketing online, o Facebook vem se mostrando um meio considerável de atingir novos consumidores, através de ações específicas e de baixo custo. Para isso o Facebook possui várias ferramentas entre elas se destacam: Perfis, anúncios, criação de grupos e fan pages. Mas as facilidades disponibilizadas por esse tipo de ação não deve ser subestimadas, toda e qualquer tipo de ação deve ser muito bem elaborada, porque o Facebook possui uma capacidade viral muito alta, e um post mal interpretado pode causar grande prejuízo para sua campanha de marketing.

\subsection{Comércio Eletrônico e marketing no} Twitter

O Twitter pode ter uma infinidade de aplicações no marketing digital. Um ponto positivo a ser observado no Twitter é a grande utilização de dispositivos móveis usados para seu acesso (celulares, tablets e afins). Assim, os usuários atingidos por suas ações não se limitam apenas as pessoas sentadas a frente de um computador, pode chegar a qualquer pessoa, em qualquer lugar.
"Brito (2009) enfatiza alguns pontos para o sucesso no uso do comércio eletrônico, dos quais se destacam o conhecimento de seus clientes, procurando saber o que eles pensam e falam sobre sua empresa; a determinação dos objetivos organizacionais do uso da ferramenta, pois nem todas as empresas utilizam o Twitter da mesma forma, mas as que usam, realmente devem saber como utilizá-lo; e não apenas elaborar as estratégias, e sim, executar, pois as empresas geralmente perdem muito tempo em reuniões definindo estratégias que muitas vezes nem são implementadas" (PETRY,SIMONETTO, 2013).

O valor do Twitter está na capacidade de alcançar um grande nicho de audiência de pessoas que estão interessadas no que você tem a dizer (REED, 2012), dessa forma o Twitter se mostra como uma ferramenta muito útil para se relacionar de forma direta com seus clientes e colaboradores.

\section{Método de Pesquisa}

Para o presente estudo, foram selecionadas cinco empresas que estão entre as 10 mais bem colocadas no ranking do site ECommerce Brasil (ECOMMERCE, 2012). As mesmas foram nomeadas como Empresa A, B, C, D e E, para assim preservar suas identidades.

A coleta dos dados foi realizada entre os dias 15/03/2014 e 15/04/2014, e a coleta foi executada de forma distinta para o Twitter e Facebook. No Twitter a coleta foi feita de 
forma manual, diariamente nos perfis das empresas pesquisadas. Já no Facebook, as coletas foram feitas com o auxílio do programa Quintly, disponível para uso na internet. O programa permite buscar diversas informações de uma fan page através do endereço eletrônico da empresa no Facebook, através de uma interface simples e amigável.

Os dados foram armazenados em planilhas eletrônicas e a pesquisa estatística foi elaborada de acordo com um estudo sobre o Twitter realizado por Thoring (2011),

Para realizar o estudo comparativo entre o Twitter e o Facebook, foram necessária algumas adaptações no modelo proposto. $\mathrm{Na}$ análise quantitativa a comparação foi baseada no número de posts e tweets por dia, horário e dias da semana dos mesmos, enquanto que na analise qualitativa os posts e tweets foram classificados como sendo informativos, relacionamento com os clientes e divulgação de promoções. Após ser feita a análise estatística, chegou-se aos resultados que estão expostos no decorrer deste artigo.

\section{Análise dos dados}

Após coletar os dados das empresas, realizouse a análise das atividades relacionadas ao uso do Facebook e Twitter durante o tempo estipulado para a pesquisa. As empresas foram avaliadas de forma conjunta, após todas as coletas serem realizadas, os dados das 5 empresas foram somadas respectivamente na rede social a qual foi coletada, tendo o objetivo ver as diferenças de uso entre essas duas redes sociais. Após as análises foram feitas considerações, no que tange a pesquisa tanto na análise quantitativa quanto na qualitativa, e essas observações estão expostas a seguir.

\subsection{Análise Quantitativa}

Para a análise quantitativa dividimos em três etapas, primeiramente foi analisado o Facebook individualmente, após isso analisou-se o Twitter individualmente e, por fim, comparou-se os resultados das duas redes sociais. As analises realizadas estão especificadas a seguir.

\subsubsection{Análise das redes sociais}

$\mathrm{Na}$ figura1 pode-se verificar a porcentagem do número total de tweets de cada empresa, nota-se que a empresa $\mathrm{C}$ foi a que mais postou em sua página, seguido da empresa $B$ e empresa E, a empresa que obteve um número de postagem muito abaixo foi a empresa D.

Figura1-Figura com totais dos posts Twitter

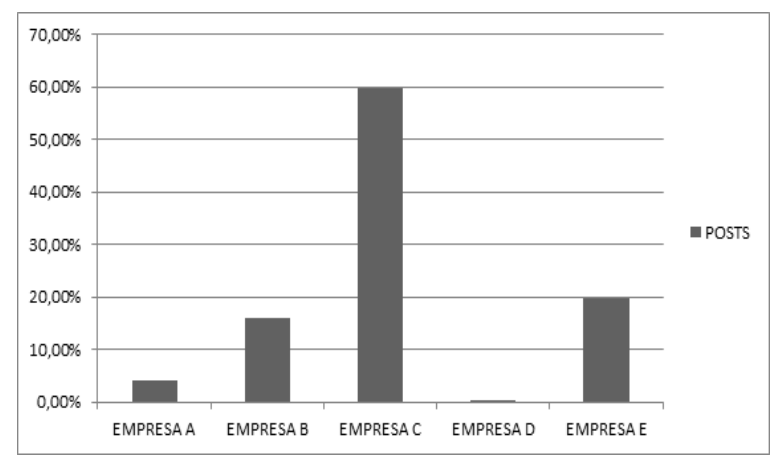

Fonte - Autores (2014)

O mesmo método foi utilizado para demonstrar o uso do Facebook pelas empresas, a figura 2 demonstra o comparativo de uso de cada empresa em suas fan pages. 
Figura 2 - Figura com totais dos posts no Facebook

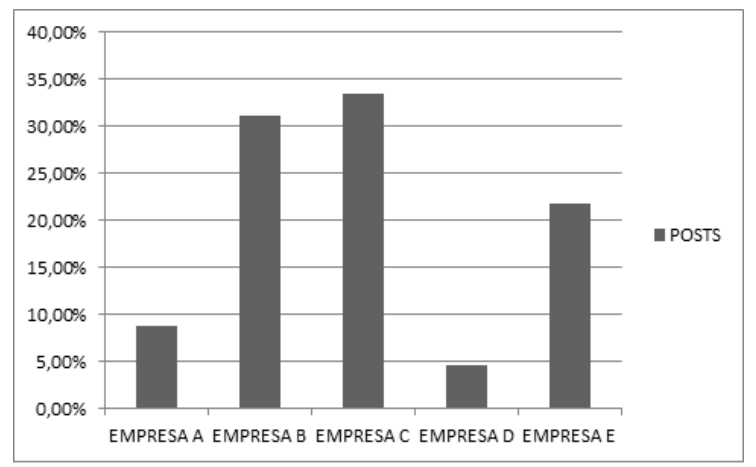

Fonte - Autores (2014)

Nota-se que a empresa C com 33,52\% das postagens totais foi a que mais utilizou sua $f a n$ page, seguida de perto pela empresa $\mathrm{B}$ com $31,17 \%$, já a empresa $\mathrm{D}$ foi novamente a empresa que menos utilizou da rede social.

\subsubsection{Análise comparativo entre redes sociais}

Foram realizadas 4 tipos de coletas entre as empresas que serviram de auxílio para a construção dessa comparação. Em ambas redes sociais foram analisados qual delas foi mais utilizada, os horários dos posts/ tweets e os dias da semana utilizados com maior frequência.

$\mathrm{Na}$ figura 3 está representado o total dos posts e tweets das empresas analisadas, no Twitter houve um maior número de tweets entre às

Figura 3 - Comparativo dos horários utilizados
16:00 horas e 17:00 horas com $10 \%$ do total colhido, o segundo horário mais utilizado com 9,23\% foi das 11:00 horas até 12:00 horas, durante as 3 horas da manhã e as 7 horas da manhã as paginas das empresas analisadas não foram utilizadas.

No Facebook o maior número de postagem nas fan pages foi entre as 14 horas e 15 horas com $15,39 \%$ dos posts totais, o segundo maior número de postagem foi no turno da manhã entre as 10 horas e 11 horas com $9,87 \%$ dos posts totais, dentre as 23 horas e as 5 horas da manhã as fan pages não foram utilizados.

O Twitter foi mais utilizado durante $\mathrm{o}$ período das 11 às 13 horas, esse período de tempo normalmente é um tempo de folga que os alunos ou trabalhadores possuem para descansar e consequentemente existem mais usuários conectados nesse período de tempo, outro diferencial dessa rede social é de ser a única a manter alguma atividade durante a madrugada.

A rede social com um maior número de uso durante o turno da manhã e o turno da tarde foi o Facebook com 41,04\% e 45,18\%,

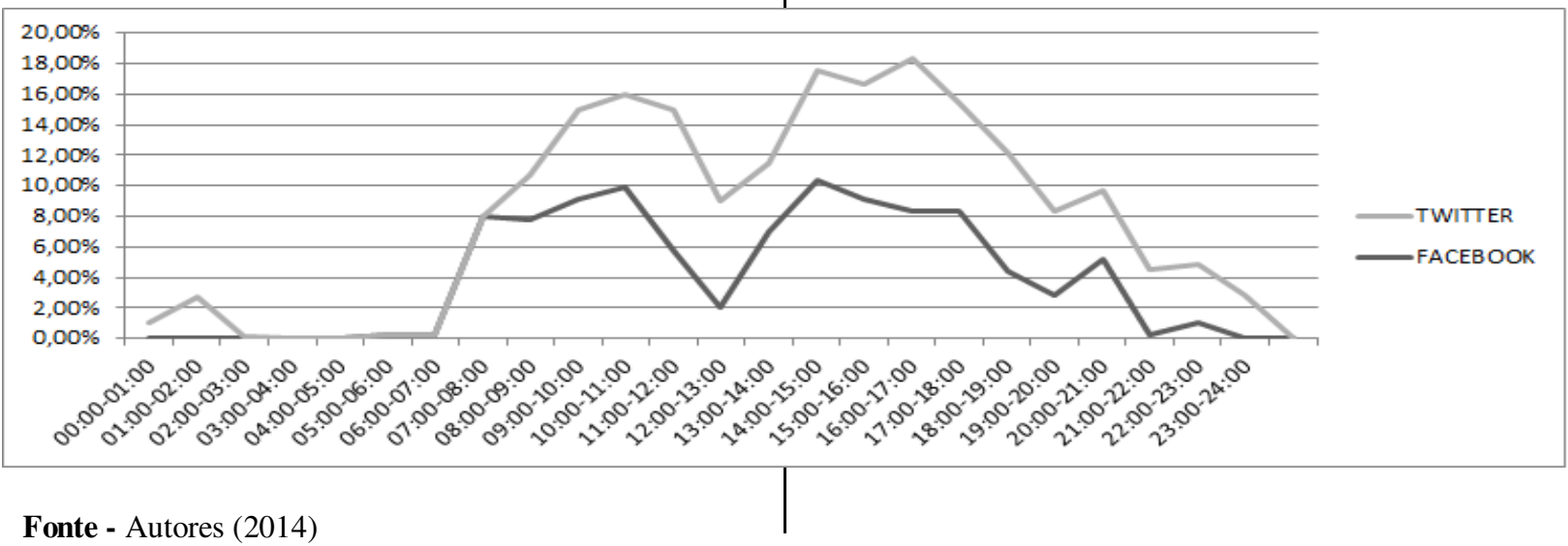


respectivamente, do total de posts, o turno da noite a rede social que mais à utilizou foi $o$ Twitter com $28,57 \%$ dos tweets totais.

Verifica-se, em faixas de horas, que tanto o Twitter, como o Facebook possuem um acréscimo de posts/ tweets em suas páginas ou fan pages, no período compreendido entre às 14 horas e às 16 horas, um número maior de informação chega até os usuários e, também, entre às 03 horas e 04 horas ambas redes sociais não são utilizadas.

$\mathrm{Na}$ figura 4 consta um comparativo entre a semana, o objetivo principal era verificar se existia alguma diferença de frequência de inclusão de informação e se algum dia era mais usado em alguma das redes sociais.

Figura 4 - Demonstrativo posts/tweets e os dias da semana

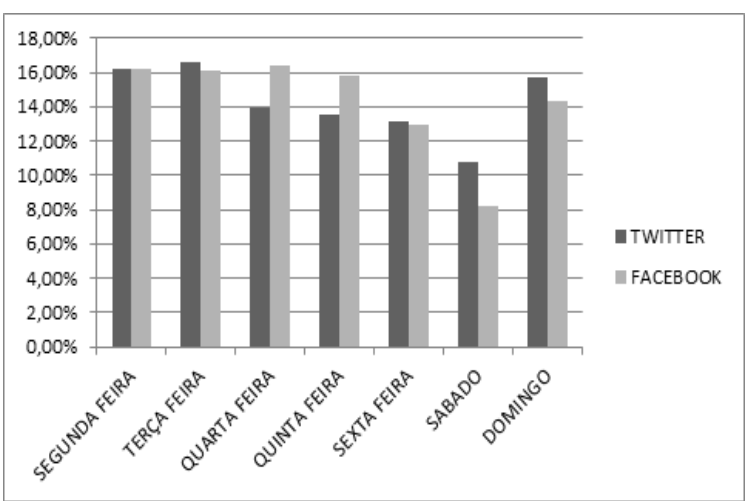

Fonte - Autores (2014)

Observe-se que as redes sociais sofrem um decréscimo de inclusão de informação após segunda feira, mas com a chegada do domingo voltam a ter um acréscimo de informação em sua fan page ou pagina pessoal. Um dos objetivos de analisar os dias da semana era verificar se existia alguma diferença na inclusão de informação entre os dias de semana e o final de semana, através da figura 5 denota- se que a diferença no Facebook é maior que a diferença exposta no Twitter, já que nas duas redes sociais o número de posts ou tweets é maior nos dias da semana, mas a diferença é pequena.

Figura 5 - Comparativo entre dias da semana e finais de

semana

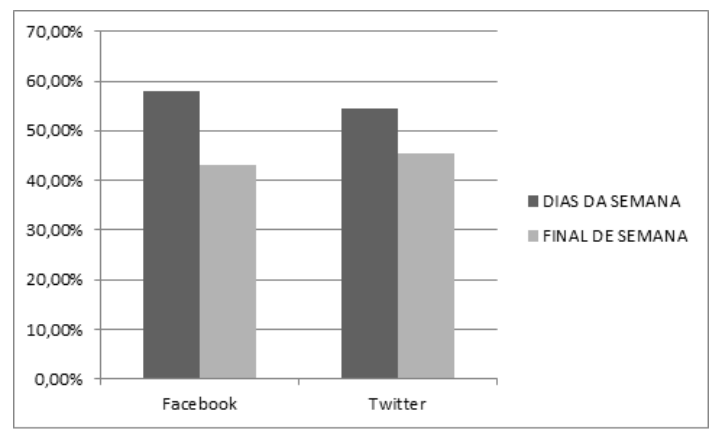

Fonte - Autores (2014)

Por final foi verificado qual rede social foi mais utilizada, através da figura 6 pode-se notar que o Twitter é muito mais utilizado como uma via de comércio eletrônico que o Facebook.

Figura 6 - Total de atividades

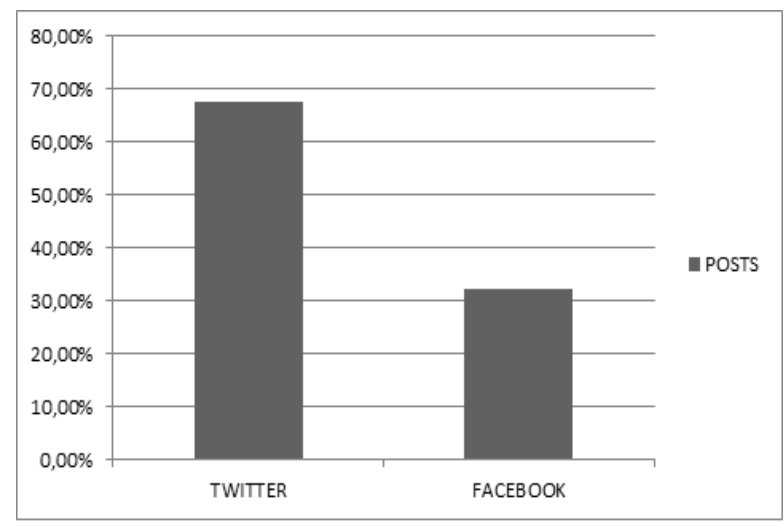

Fonte - Autores (2014)

\subsection{Análise Qualitativa}

Para a análise qualitativa, foram levados em consideração os tipos das postagens e tweets, analisando se o conteúdo inserido pelas empresas nas redes sociais tinham 
como objetivo informar seus produtos, se relacionar com seus clientes ou divulgar promoções, Os resultados totais estão expressos na Figura 7.

Tabela 7 - Comparativo entre os tipos de postagem

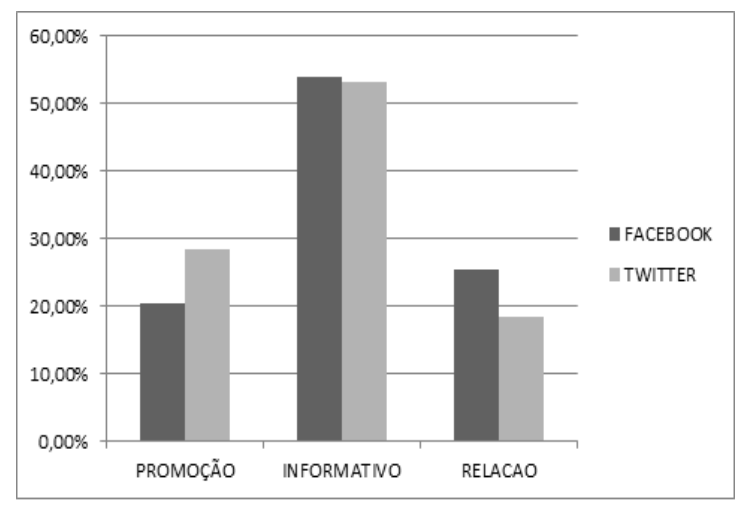

Fonte - Autores (2014)

Nota-se que estas empresas utilizaram tanto o Facebook como o Twitter para informar dados sobre seus produtos, no Twitter os tweets faziam uma ligação para a página da determinada empresa, normalmente encaminhava para um link onde continha alguma promoção, as fan pages do Facebook buscaram mais uma relação com o cliente do que as páginas pessoais de cada empresa contidas no Twitter, já as empresas no Twitter twitavam mais promoções para os clientes do que as fan pages das empresas no Facebook.

\section{Considerações Finais}

Todo o estudo elaborado nesse artigo teve como propósito principal analisar o comportamento de empresas brasileiras, apresentadas no site E-Commerce Brasil (ECOMMERCE, 2012) que estão entre as dez maiores usuárias do comércio eletrônico, em duas redes sociais o Facebook e o Twitter respectivamente. Observando-se o total de dados coletados, nota-se que a rede social mais utilizada pelas empresas foi o Twitter, todas as empresas utilizavam suas redes sociais para informação. No Facebook $53,94 \%$ dos posts tinham esse foco principal, o Twitter possuía uma diferença nesse quesito, $53,11 \%$ de seus tweets utilizados buscavam, além da informação sobre o produto, chamar a atenção do cliente para alguma promoção, onde o cliente só teria acesso clicando em um link disposto no tweet. Outro dado interessante na comparação entre as duas redes sociais, foi a diferença entre os horários de uso das fan pages e páginas no Twitter, essa própria utilizou-se mais da rede social entre às 11 horas e 12 horas, 9,23\% de seus tweets foram realizados nesse horário, 14,86\% dos tweets foram realizados entre às 17 e 19 horas, um horário onde os usuários normalmente saem de seus locais de serviço, estudo etc. No Facebook o momento onde houve uma maior frequência de postagem foi das 14 horas até 18 horas, o limite máximo de postagem foi entre às 14 horas e 15 horas, $10,39 \%$ dos posts foram para as fan pages nessa faixa de horas.

Por final, verificou-se que as empresas utilizaram mais as redes sociais nos dias da semana do que nos finais de semana, mas os dias de maior uso variou de uma para a outra, a terça feira foi mais utilizada pelo Twitter com 16,61\%, o Facebook utilizou 
mais a quarta feira, $16,42 \%$ de seus posts foram utilizados nesse dia.

Esse estudo foi importante para analisar a diferença de uso de cada Notou-se alguns pontos em comum entre o uso dessas duas redes sociais além de diferenciar a frequência de uso de ambas.

\section{Referências}

BRITO, M. (2009), 10 Twitter Best Practices for Brands. Mashable.com, Disponível em http://mashable. com/2009/06/24/Twitterbrand-best-practices (Acesso em 27 de Outubro de 2012).

CAMPANO, J. (2009), Introdução ao ECOMMERCE e questões de USABILIDADE，JM DIGITAL. Disponível em: $\quad$ http://www.jmdigital.com.br/Download_Ebook_Gratis.asp (Acesso em 07 de novembro de 2013).

E-COMMERCE BRASIL (2012), TOP 10 Lojas Online Brasileiras 2010/2011, disponível em: http://www.ecommercebrasil.org/numeros/top10-maioreslojas-online (Acesso em 10 de maio de 2014).

MARTELETO, R.M. (2009), Análise de redes sociais: aplicação nos estudos de transferência da informação. Ciência da Informação, Brasília, v. 30, n. 1, pp. 71-81.

NETO, J.L.C., YOSHITAKE,M.,FRAGA,M. S., VASCONCELOS,Y. L.(2010), COMÉRCIO ELETRÔNICO: ANÁLISE DOS FATORES CRÍTICOS, Revista Acadêmica Business Review , 2010, n 9 , disponível em: http://www.unifin.com.br/Content/arquivos/201 11006193032.pdf

PETRY,A.C., SIMONETTO, E.O (2013), USO DO TWITTER COMO CANAL DE
MARKETING: UMA ANÁLISE DAS

PRINCIPAIS EMPRESAS BRASILEIRAS

DE COMÉRCIO ELETRÔNICO, Revista

Eletrônica Sistemas \& Gestão, 2013, v 8, n

1, p.94-104 disponível em:

http://www.uff.br/sg/index.php/sg/article/vie wFile/V8N1A9/V8N1A9

RAMALHO, J.(2012), Mídias Sociais na prática, 1 ed, Elsevier, Rio de Janeiro, RJ.

REED, J. (2012), Marketing Online, como usar sites, blogs, redes sociais e muito mais, 1 ed, LaFonte, São Paulo, SP.

THORING, A. (2011). Corporate Tweeting: Analysing the Use of Twitter as a Marketing Tool by UK Trade Publishers. Pub Res Q, 27:141-158. 